Canadian

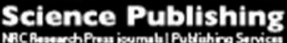

Biochemistry and Cell Biology

Biochimie et biologie cellulaire

\title{
Modulation of amyloid assembly by glycosaminoglycans: from mechanism to biological significance
}

\begin{tabular}{|r|l|}
\hline Journal: & Biochemistry and Cell Biology \\
\hline Manuscript ID & bcb-2016-0236.R1 \\
\hline Manuscript Type: & Mini Review \\
\hline Date Submitted by the Author: & $25-J a n-2017$ \\
\hline Complete List of Authors: & $\begin{array}{l}\text { Quittot, Noe; Universite du Quebec a Montreal, Chemitsry } \\
\text { Sebastiao, Mathew; Universite du Quebec a Montreal, Chemitsry } \\
\text { Bourgault, Steve; Universite du Quebec a Montreal, Chemitsry }\end{array}$ \\
\hline Keyword: & Glycosaminoglycan, Amyloid, Self-assembly, Protein, Peptide \\
\hline
\end{tabular}

\section{SCHOLARONE \\ Manuscripts}


Modulation of amyloid assembly by glycosaminoglycans: from mechanism to biological significance

Noé Quittot, Mathew Sebastiao and Steve Bourgault

Department of Chemistry, Pharmaqam, University of Québec in Montreal, Montreal, QC, Canada, $H 3 C 3 P 8$

Quebec Networkfor Research on Protein Function, Engineering, and Applications, PROTEO

*Corresponding author:

Pr. Steve Bourgault,

Université du Québec à Montréal

C.P. 8888 , Succursale Centre-Ville

Montréal (Québec), H3C 3P8, Canada

$1-514-987-3000(5161)$

bourgault.steve@uqam.ca 


\begin{abstract}
:
Glycosaminoglycans (GAGs) are long and unbranched polysaccharides that are abundant in the extracellular matrix and basement membrane of multicellular organisms. These linear polyanionic macromolecules are involved in many physiological functions, from cell adhesion to cellular signaling. Interestingly, amyloid fibrils extracted from patients afflicted with protein misfolding diseases are virtually always associated with GAGs. Amyloid fibrils are highly organized nanostructures that have been historically associated with pathological states, such as Alzheimer's disease and systemic amyloidoses. However, recent studies have identified functional amyloids that accomplish crucial physiological roles in almost all living organisms, from bacteria to insects and mammals. Over the last two decades, numerous reports have revealed that sulfated GAGs accelerate and/or promote the self-assembly of a large diversity of proteins, both inherently amyloidogenic and non-aggregation prone. Despite the fact that many studies have investigated the molecular mechanism(s) by which GAGs induce amyloid assembly, the mechanistic elucidation of GAG-mediated amyloidogenesis still remains the subject of active research. In this review, we expose the contribution of GAGs in amyloid assembly and we discuss the pathophysiological and functional significance of GAG-mediated fibrillization. Finally, we propose mechanistic models of the unique and potent ability of sulfated GAGs to hasten amyloid fibril formation.
\end{abstract}

Keywords: Glycosaminoglycan; Amyloid; Self-assembly; Protein; Peptide 


\section{Introduction}

Amyloid fibrils are ordered protein assemblies that are characterized by a cross- $\beta$-sheets quaternary structure (Chiti and Dobson 2006). These insoluble protein nanostructures, which were historically associated with different pathological states, are now perceived as a generic low energy conformation that can be adopted by the vast majority of known polypeptide chains. Over 30 human proteins whose deposition is associated with diseases have been identified so far, including the amyloid- $\beta(\mathrm{A} \beta)$ peptide associated with the Alzheimer's disease, the islet amyloid polypeptide (IAPP) linked to type II diabetes and transthyrethin (TTR) related to systemic amyloidoses. These protein misfolding diseases differ by the protein that deposits as insoluble aggregates and by the tissues subjected to deposition and degeneration (Cohen and Kelly 2003). Interestingly, recent studies have identified amyloid structures that accomplish essential physiological activities in living organisms that utilize these assemblies for their unique biological and mechanical properties. These functional amyloids have been reported in almost all species, from bacteria to insects and mammals (Fowler et al. 2007). In humans, the protein Pmel17 adopts an amyloid quaternary structure in order to sequester the reactive quinones generated during melanin biosynthesis, a key process in skin pigmentation (Fowler et al. 2006). In Gram-negative bacteria, the protein curli self-assembles into cross- $\beta$-sheets fibrils, constituting a major component of bacteria biofilm (Blanco et al. 2012). The remarkable mechanical, physical and biological properties of amyloids suggest that these nanostructures hold great potential as nanomaterials for technological and nanomedical applications. For instance, amyloid fibrils are being developed as molecular scaffolds for vaccine development (Rudra et al. 2010), for tissue and cell engineering (Branco et al. 2011) and for drug delivery (Bhak et al. 2010). 
Thus, understanding the molecular mechanism(s) by which a protein self-assembles into organized amyloid fibrils is an important area of research from fundamental, medical and technological perspectives. Polypeptide self-assembly in vivo takes place in a crowded and heterogeneous biological environment. Notably, amyloid fibrils extracted from living organisms are virtually always associated with diverse biomolecules, such as proteins (serum amyloid P component, apolipoprotein E, collagen) (Kisilevsky 2000), metal ions (Alexandrescu 2005), lipids (Gellermann et al. 2005) and glycosaminoglycans (GAGs) (Ancsin 2003). These co-factors were initially considered to be contaminants of the amyloids and in vitro mechanistic studies were exclusively performed with homogenous protein solutions. Over the last two decades, several studies have highlighted that these amyloid cofactors modulate the kinetics and/or the pathways of the amyloidogenic process. Predominantly, sulfated GAGs are now recognized as central cofactors in the process of amyloid assembly and GAG-modulated amyloidogenesis appears to play critical (patho)physiological roles. In this review, we will initially expose the major contributions of GAGs in amyloid formation, both for inherently amyloidogenic and non-amyloidogenic peptides and proteins. After briefly presenting the structure and function of amyloids and GAGs, we will emphasize the mechanistic roles of GAGs in amyloid assembly. Finally, we will discuss the potential biological implications of GAG-induced amyloid formation, both from pathological and functional points of view.

\section{Glycosaminoglycans: promotors of amyloid assembly}

GAGs are polyanionic polysaccharides that are abundant in the extracellular matrix, basement membrane and on the outer leaflet of the plasma membrane of multicellular organisms. These linear and unbranched polysaccharides are ubiquitously associated with amyloid deposits 
linked to protein misfolding diseases (Iannuzzi et al. 2015), including those from TTR (Inoue et al. 1998), A $\beta$ (DeWitt et al. 1993), IAPP (Young et al. 1992), $\beta 2$-microglobulin (Ohishi et al. 1990) and immunoglobulin light chain (Stenstad et al. 1991). These studies have suggested a causative role of sulfated GAGs in the fibrillogenesis and deposition of a variety of amyloidogenic polypeptides and have prompted biophysical investigations. As a matter of fact, numerous studies have reported that sulfated GAGs accelerate and/or induce the amyloid assembly from peptides and proteins associated with amyloid-related diseases, including the prion protein (Perez et al. 1998), gelsolin (Suk et al. 2006), immunoglobulin light chain (McLaughlin et al. 2006), A $\beta$ (McLaurin et al. 1999), $\alpha$-synuclein (Cohlberg et al. 2002), $\beta 2$-microglobulin (Relini et al. 2008) and TTR (Bourgault et al. 2011b). Strikingly, GAGs also prompt amyloid assembly of polypeptides that are inherently non-amyloidogenic, highly soluble and not associated with pathological states (Madine et al. 2013). For example, many soluble and intrinsically non-aggregating peptide hormones can self-assemble into amyloid-like nanostructures in presence of sulfated GAGs (Maji et al. 2009). A non-exhaustive list of polypeptides whose self-association into amyloids is accelerated and/or induced by sulfated GAGs is included in Table 1. Overall, GAGs appear as potent amyloid enhancers for many peptides and proteins, although clear mechanistic insights of their contributions to amyloidogenesis still remain elusive.

\section{Molecular architecture of amyloid fibrils}

Given that amyloids are inherently non-crystalline and insoluble, common techniques to determine protein structure such as X-ray crystallography and liquid state nuclear magnetic resonance (NMR) are inconvenient. Thus, structural characterization of amyloid fibrils is usually performed by electron paramagnetic resonance and solid-state NMR (SSNMR) (Tycko 2015). 
By atomic force microscopy (AFM) and electron microscopy (EM), amyloids extracted from patients or prepared in vitro appear as long $(0.5$ to $10 \mu \mathrm{m})$ and unbranched filaments having a diameter of 3 to $15 \mathrm{~nm}$ (Fig. 1A). Amyloid fibrils are organized hierarchically and are usually constituted of 2 to 8 protofilaments than can be either linearly packed or twisted. The high stability of the amyloid structure against thermal, chemical and enzymatic degradation resides in a combination of noncovalent bonds, notably inter-chain hydrogen bonds, $\pi-\pi$ stacking and hydrophobic interactions. Amyloid X-ray diffraction pattern is characterized by two scattering diffraction signals; a sharp reflection at $4.7 \AA$ along the direction of the fibril and a diffuse reflection at $10 \AA$ perpendicular to the fibril axis, indicating that $\beta$-strands are oriented perpendicular to the axis fibrils (Sunde et al. 1997). This cross- $\beta$-sheet organization is formed by peptide segments that adopt a secondary structure in $\beta$-strand conformation and assemble into ribbon-like $\beta$-sheets (Fig. 1B) (Tycko 2014).

Despite common structural features, amyloid fibrils display a polymorphism of their molecular structure and supramolecular arrangement. This polymorphism is ascribed to the amino acid sequence of the proteic precursor as well as the conditions in which self-assembly occurs, including the presence of GAGs. Indeed, although different polypeptides are able to form amyloid fibrils and contain identical X-ray diffraction pattern, there is a wide diversity of molecular arrangement within amyloids (Nelson et al. 2005). Studies on microcrystals formed upon the self-association of amyloidogenic polypeptides revealed that $\beta$-sheets can be oriented either parallel or anti-parallel (Sawaya et al. 2007). Moreover, one polypeptide can have several segments in $\beta$-strand secondary structure and each of these $\beta$-strands can be part of one or more $\beta$-sheet layers (Tycko 2015). For instance, depending on the conditions in which assembly occurred, three structural models were proposed for the $\mathrm{A} \beta(1-40)$, the most studied amyloidogenic peptide. 
Two of these structural models describe a monomer with a disordered N-terminal domain and two segments in $\beta$-sheet conformation, where each $\beta$-strand participates in two different parallel in-register $\beta$-sheets (Paravastu et al. 2008; Petkova et al. 2006). The two segments are linked by a loop and monomers are stack along the fibril axis. The third model was proposed from fibrils grown in the presence of amyloids extracted from brain tissue of a patient afflicted with Alzheimer's disease and is also composed by a three-fold rotational symmetry (Lu et al. 2013). Two models were recently proposed for $A \beta(1-42)$ fibrils in which monomers adopt an S-shape and are composed of four short $\beta$-strands (Colvin et al. 2016; Wälti et al. 2016). Thus, these studies highlight that the addition of two additional amino acids at the C-terminal end can lead to drastic alterations of the amyloid structure, indicating that fibril morphology is very sensitive to modifications within the primary sequence.

\section{Mechanisms of amyloid assembly}

Polypeptide chains that are prone to self-assemble into amyloids can be divided in two categories. On one hand, proteins characterized by an ordered/globular native structure need to unfold or partially unfold to self-associate into amyloid fibrils. Transthyretin (TTR) (Bourgault et al. 2011a), 32-microglobulin (Stoppini and Bellotti 2015) and immunoglobulin light chain (Wolwertz et al. 2016) are good examples of natively folded proteins whose deposition is associated with pathological states. On the other hand, intrinsically or partially disordered polypeptides, such as IAPP, A $\beta$ and $\alpha$-synuclein, need to undergo conformational rearrangements allowing the formation of ordered segment(s) to initiate amyloid assembly (Abedini and Raleigh 2009). The mechanism of amyloid assembly is still the matter of active debate and different models have been proposed. Generally, amyloid formation is ascribed as a nucleated polymeriza- 
tion (Bemporad and Chiti 2012). This model is characterized by the formation of an energetically unfavorable oligomeric nucleus as the rate-limiting step. Once the nucleus is formed, assembly occurs rapidly through the addition of competent monomers, or oligomers, to the growing end of the protofibrils. This amyloidogenic process can also be seen as a three steps mechanism where the (i) lag phase, (ii) elongation phase and (iii) saturation phase are governed by different kinetics (Fig. 2). During the lag phase, transient and dynamic oligomers are formed in equilibrium with monomers until the high-energy nucleus is reached. This initial phase occurs slowly because of the unfavorable interactions between monomers. As soon as the nucleus is formed, the elongation phase begins, leading to the rapid growth of the biopolymers. Other kinetic models have also been suggested, such as downhill polymerization (Hurshman et al. 2004), monomerdirected conversion (Prusiner 1982) and nucleated conformational conversion (Lee et al. 2011). Nonetheless, these mechanisms were inferred from in vitro studies in homogenous aqueous solution and the amyloidogenic pathway is likely to be different in the crowded and heterogeneous environment of living organisms (Nguyen et al. 2015). GAGs are well-known for their unique and potent capacity to modify the kinetics of amyloid assembly for both globular and intrinsically disordered polypeptides.

\section{Structure and function of glycosaminoglycans}

In multicellular organisms, the extracellular matrix (ECM) forms an essential structural and (bio)chemical scaffold for cells and is involved in the regulation of many physiological processes, such as cell differentiation and migration and morphogenesis (Theocharis et al. 2016). Fibrous proteins, proteoglycans (PGs) and GAGs are the most abundant components of the ECM. PG consists of a core protein that is covalently linked to one or more GAG chains. GAGs 
are negatively charged polysaccharides formed by the repetition of disaccharides and can reach up to 200 disaccharide units (Bishop et al. 2007). Disaccharidic units are principally formed by D-/L-hexuronic acid, D-glucuronic acid or L-iduronic acid, and N-acetylated hexosamine, Nacetyl-D-galactosamine or N-acetyl-D-glucosamine. Accordingly, GAGs are classified in two groups: (i) galactosaminoglycans including chondroitin sulfate and dermatan sulfate and (ii) glucosaminoglycans including heparan sulfate, heparin, keratan sulfate and hyaluronan (Fig. 3). The expression level and chemical nature of GAGs at the cell surface and in the ECM differ among tissues and cell types. Heparan sulfate is the most ubiquitous GAG and is expressed by almost all eukaryotic cell types (Moremen et al. 2012). Owing to their high density in carboxylate and sulfate groups, GAGs have a unique capacity of interacting with a large diversity of biomolecules. GAG chains of PGs are known to recruit and sequester numerous soluble protein ligands, including chemokines, cytokines and growth factors (Handel et al. 2005). These interactions confer key roles to GAGs in many important physiological processes such as inflammation, cell signalling and organogenesis.

\section{Nature of GAG-polypeptide interactions}

Among peptides and proteins that are recognized to spontaneously self-assemble into amyloids, there is an obvious propensity towards interactions with GAGs. These interactions were shown to be somewhat non-specific to any single category of peptide or protein, requiring only the GAG being polyanionic (Abedini et al. 2006; Castillo et al. 1998). Driving forces of polypeptide-GAG binding mainly arise from electrostatic interactions between anionic sulfate groups of the polysaccharide and the cationic residue side chains. Whereas early studies advocated that histidine residues contribute minimally to GAG-binding (Cardin and Weintraub 1989), recent 
works have suggested that this may not be the case. Many amyloidogenic processes, in absence or in presence of GAGs, are $\mathrm{pH}$ sensitive within a physiologically relevant window. For example, the stability of amyloid fibrils assembled in presence of GAGs at $\mathrm{pH} 5.5$ is reduced at a physiological pH of 7.4 (Maji et al. 2009; Stewart et al. 2016). Similarly, rates of amyloid formation can vary greatly between $\mathrm{pH} 7.4$ and 5.5. These two $\mathrm{pH}$ values coincide well with either side of the pKa of the imidazole group (@6), supporting the notion that histidine residues are involved in GAG binding and/or GAG accelerated amyloidogenesis (Malmos et al. 2016). Counter-ion condensation theory (CCT) was proposed to explain the importance of histidine residues for $\mathrm{A} \beta-\mathrm{GAG}$ binding. $\mathrm{CCT}$ postulates that with a sufficient charge density, linear polyanions can be partially neutralized by cations in solution, causing a cloud of positive ions around GAGs (Muthukumar 2004). The displacement of this cationic cloud by the peptide would result in an entropically favourable interaction. This CCT model may explain why in the presence of high sodium concentrations, $>250 \mathrm{mM}$, GAG-mediated fibrillization is hindered (Nguyen and Rabenstein 2016). As the bulk cation concentration becomes too high, it is no longer as entropically favourable to displace the cluster of cations into the water.

Two specific amino acid sequences involving alternating basic and non-basic residues were initially proposed as GAG-recognition motif: $\mathrm{XBBXB}$ and $\mathrm{XBBBXXBX}$; where $\mathrm{X}$ is an uncharged, hydrophobic residue and B is a cationic residue (Cardin and Weintraub 1989). Other GAG-binding motifs have also been proposed, including $\mathrm{XBBX}_{\mathrm{n}} \mathrm{BX}(\mathrm{n} \leq 2)$ and $\mathrm{XBBB}_{\mathrm{n}} \mathrm{X}(\mathrm{n} \geq$ 1) (Hileman et al. 1998; Proudfoot et al. 2001). However, it is important to remind that an increased ability to bind GAGs does not necessarily correlate with the ability of a given polypeptide to self-assemble in the presence of GAGs. There appears to be a fundamental distinction between GAGs demonstrating the ability to bind polypeptides, such as cytokines, cell- 
penetrating-peptides or growth factors, and their capacity to induce the formation of ordered amyloid fibrils (Handel et al. 2005; Tchoumi Neree et al. 2014). Due to uncertainties regarding the specific mechanism(s) which allow proteins to form amyloid in the presence of GAGs, it is unclear whether increased ability to bind GAGs is even positive from a mechanistic point of view. If the peptide-GAG interaction is transitory and dynamic throughout the amyloidogenic pathway, then excessively strong GAG binding could, in fact, inhibit amyloid formation. In this view, the stability of the GAG-chemokine complex could prevent the self-association of the signaling protein.

It was reported that GAG binding affinity towards amyloid nanostructures assembled under homogeneous conditions varies according to the supramolecular organization of the fibrils (Stewart et al. 2016). Using methionylated $A \beta(1-40)$, it was observed that distinct amyloid morphologies engage into different assemblies with GAGs. Certain fibril morphologies create welldefined binding pockets into which GAGs can solidly rest through electrostatic interactions (Stewart et al. 2016). This observation offers insights as to why the presence of GAGs induces specific fibril morphologies in heterogeneous system. Thus, the presence of GAGs during the assembly reaction could shift the reaction equilibria towards amyloid structures with GAGaccepting morphologies. Interestingly, it was showed that different GAG:polypeptide molar ratios result in variable fibril morphologies (Bazar and Jelinek 2010). Unfortunately, the degree to which this effect takes place, as well as the final product remains impossible to predict beforehand.

\section{Properties of GAGs mediating amyloidogenesis}


Chemical and structural GAG properties were reported to be critical for their effect on amyloidogenesis, including ( $i$ ) the length of the polysaccharide chain, (ii) the degree of sulfation and (iii) the GAG:polypeptide molar ratio. The degree of polymerisation (dp) is of primary importance for fibrillogenesis (Bourgault et al. 2011b; Jha et al. 2011; Stewart et al. 2016; Takase et al. 2016). At short lengths (dp $\leq 4)$, GAGs exert minimal effect on the rate of amyloid formation. This could be attributed to an insufficient ability to cluster the starting material, i.e. individual polypeptides and/or pre-fibrillar oligomers. At intermediate lengths (dp6 - dp12), the lag phase of fibril formation for most proteins is markedly reduced (Fraser et al. 2001). Generally, fibrillization is accelerated with increasing oligosaccharide size, although for some systems, the effect on fibril assembly plateaus when the chain length becomes sufficiently long (dp 》18) (Jha et al. 2011; Takase et al. 2016). In addition, the density and distribution of sulfated groups along the polysaccharides also appear to be critical. For TTR, a direct correlation between the rate of fibrillization and the density of sulfate groups was reported, with heparin being more effective than heparan sulfate and $\mathrm{N}$-acetylated heparin (Bourgault et al. 2011b). In contrast, heparan sulfate appears to be more effective than its highly-sulfated counterpart heparin to hasten the nucleation step of A $\beta$ (McLaurin et al. 1999). Although divergences exist among studied systems, the overall trend is that the high density of sulfate groups and the polymeric nature of GAGs are essential features for accelerating amyloid assembly.

The relative concentration of GAGs also influences fibrillization and the relationship is not as simple as initially anticipated. A study specifically addressed the importance of GAG:peptide ratio using heparin and the prion-related protein fragment PrP (106-126) (Bazar and Jelinek 2010). When heparin was present in equal or greater quantities than $\operatorname{Pr} P(106-126)$, i.e. in molar ratios of 5:1, 2:1, and 1:1 (heparin:PrP), fibril formation did not occur. However at 0.5:1 and 
0.2:1 molar ratios (heparin:PrP), fibril formation was observed at increasing rates. As the relative concentration of heparin was further decreased to 0.1 , the effect became less pronounced, signifying an optimal range of molar ratios. Thus, it appears that at a molar ratio of $0.5: 1$ there is sufficient GAGs to interact with prion fragments while simultaneously not being so excessive to result in a low local concentration of peptides (Bazar and Jelinek 2010). This observation supports the notion that GAGs accelerate amyloid formation by increasing the local concentration of pre-fibrillar species. Nonetheless, the authors could not differentiate between GAGs binding individual peptides and/or pre-fibrillar intermediates, a central question that will be discussed below.

\section{Mechanistic contributions of GAGs in amyloid assembly}

Owing to the association between amyloid deposition and GAGs, investigations of the molecular mechanisms of GAG-induced self-assembly were initially performed with polypeptides whose deposition is associated with pathological states. Interestingly, over the last five years, mechanistic studies have also been performed with non-amyloidogenic polypeptides. The most noticeable effects of GAGs on the process of amyloid formation are $(i)$ the sharp reduction of the lag phase, (ii) the marked increase in the rate of fibrillization that occurs in the elongation phase and/or (iii) the supramolecular organization of the amyloid assemblies (Fig. 2; red dashed line). For a wide variety of polypeptides, the addition of GAGs into the aggregation solution decreases severely the lag-phase, almost even eliminating it in certain cases. The rapid and immediate effect of the addition of heparin, commonly used to mimic the sulfated domains of heparan sulfate, is particularly noticeable for the non-amyloidogenic polypeptide $\operatorname{PLB}(1-23)$, a 23-residue fragment of the protein phospholamban. On its own, this peptide demonstrates no ability to form fibrils, yet upon addition of heparin to the solution, a prompt increase in thioflavin T (ThT) fluo- 
rescence was observed (Madine et al. 2013). Similar effects were observed with polypeptides that are known for their propensity to aggregate and whose depositions are associated with pathological states, such as IAPP, TTR, $\beta 2$-microglobulin and apomyoglobin (De Carufel et al. 2013; Noborn et al. 2011; Relini et al. 2008; Vilasi et al. 2011). Whether this occurs because GAGs directly influence the conformational transition between the native and amyloidogenic states and/or because GAGs increase the local concentration of pre-fibrillar species remains to be confirmed.

The mechanistic contributions of GAGs in the fibrillization of TTR have been investigated and disparity exists between the two proposed models (Bourgault et al. 2011b; Noborn et al. 2011). TTR is a homotetrameric protein involved in the transport of thyroxine and holo-retinolbinding protein. The aggregation and deposition of TTR is associated with amyloidoses such as familial amyloidotic polyneuropathy and familial amyloidotic cardiomyopathy. Although recombinant TTR and its amyloidogenic variants can self-assemble under certain conditions (i.e. low $\mathrm{pH}$ ), the addition of sulfated GAGs to the system enhances amyloidogenesis. The mechanism was initially described as a quaternary structural conversion in which GAGs interact primarily with pre-fibrillar oligomers through electrostatic interactions, concentrating and orienting them and facilitating the formation of higher molecular weight aggregates (Bourgault et al. 2011b). According to this model GAGs do not affect the process by which TTR self-assembles, involving: ( $i$ ) dissociation of the tetramer into monomers, $(i i)$ partial denaturation of the released monomers, (iii) oligomerization and (iv) amyloid formation through a downhill polymerization (Connelly et al. 2010). Thus, addition of heparin into the aggregation mixture does not influence the early phase of TTR self-assembly, but rather facilitates association of oligomers. In contrast, 
Noborn and colleagues suggested that heparin/heparan sulfate interact with monomeric TTR, promoting their association into oligomers (Noborn et al. 2011).

Despite differences in molecular weight and native structure between TTR and the $8 \mathrm{kDa}$ fragment of gelsolin, a similar mechanism of GAG-induced fibrillization was proposed (Solomon et al. 2011). The secreted C-terminal $68 \mathrm{kDa}$ gelsolin fragment is known to be cleaved in the extracellular matrix to generate 8 and $5 \mathrm{kDa}$ amyloidogenic fragments, with the former being the main component of gelsolin amyloid deposits in humans (Solomon et al. 2012). Monomerized $8 \mathrm{kDa}$ gelsolin did not bind to heparin under physiological conditions whereas cross- $\beta$ sheet oligomers and amyloid fibrils bind strongly to heparin (Solomon et al. 2011). This suggests a scaffolding mechanism wherein cross- $\beta$-sheet oligomers bind to GAGs, accelerating fibril extension. In sharp contrast, by means of dynamic light scattering, it was reported that heparin promotes the formation of pre-fibrillar oligomers via the interaction with the monomeric $\beta$-2microglubulin (Relini et al. 2008).

GAGs are so potent in their ability to induce amyloid formation, that they have consistently demonstrated doing so in a variety of otherwise non-aggregating polypeptides. For instance, it was reported that peptide hormones self-assemble in presence of GAGs, although no amyloid formation was observed when these peptides were incubated alone (Maji et al. 2009). Derivatives of amyloidogenic peptide that are resistant in forming amyloids constitute a clear testimony of the unique ability of GAGs to promote self-assembly. For example, substitution of Ile-26 by a Pro residue (Abedini and Raleigh 2006) or incorporation of N-methylated residues at positions 24 and 26 prevent IAPP amyloid formation (Yan et al. 2006). Strikingly, in presence of sulfated GAGs, these two IAPP derivatives gained ability to self-assemble into amyloids (Wang et al. 2013). Fluorescence energy resonance transfer (FRET) was used to understand the interaction of 
these non-amyloidogenic IAPP analogs with GAGs. GAGs were tagged with a FRET acceptor and the amyloid-sensitive fluorophore ThT was used at the FRET donor. The observed FRET signal suggested that the donor and acceptor were near enough to transfer the excitation energy (Wang et al. 2013). This study reinforces the hypothesis that amyloids assemble along the longitudinal axis of the GAG chain. By SSNMR, it has been recently reported that the core of the amyloid-GAG complex is composed of peptide strands, while GAGs are bound to the exterior edges of these strands (Malmos et al. 2016). This study was conducted with salmon calcitonin (sCT), which is known for its resistance to self-assemble. This highlights that in presence of GAGs, a peptide with a low intrinsic amyloidogenicity assembles into fibrils that are similar to the fibrils composed of a highly amyloidogenic peptide, such as $A \beta(1-40)$ (Stewart et al. 2016).

The amyloid-inducing potential of GAGs on non-inherently amyloidgenic protein is not only limited to peptides. For instance, apomyoglobin is a non-amyloidogenic natively folded protein whereas its mutant W7FW14F is known to be amyloidogenic-prone (Vilasi et al. 2011). Upon addition of heparin, it was observed that wild-type apomyoglobin readily forms amyloid fibrils at comparable rate of the mutant form. As suggested for TTR and gelsolin, the authors postulated that the mechanism of GAG-induced amyloid formation involves an increase of the local concentration that occurs upon binding of pre-fibrillar species to GAGs. Nonetheless, the authors were unable to determine whether these precursors were monomeric or oligomeric.

Overall, our current understanding of the molecular basis of GAGs-mediated amyloidogenesis does not indicate whether the assembly of amyloid structure in the presence of co-factors such as GAGs, follows a universal mechanism, or instead if multiple case-dependent mechanisms are required to explain the observed assemblies. According to the studies described above, we can propose that GAGs accelerate amyloid assembly by one or a combination of these mod- 
els: (i) GAG-directed monomer conversion, (ii) GAG-induced oligomerization, (iii) GAGmediated quaternary structural conversion and/or (iv) GAG-enhanced fibril growth.

\section{Biological relevance of GAG-mediated amyloid assembly}

Over the last two decades, compelling pharmacological and genetic evidences have emphasized the causative link between amyloid deposition and the progression of numerous pathologies (Bulawa et al. 2012). Although the molecular arrangement of the proteotoxic species and the mechanisms of cytotoxicity still remain unclear, cell and animal studies performed with numerous amyloidogenic polypeptides have suggested that oligomers, which may or may not be on pathway to amyloid formation, are more deleterious than well-defined fibrils (Kayed et al. 2003). Reports have indicated that the process of amyloid assembly leads to cellular degeneration whereas the final assemblies, i.e. the mature amyloid fibrils, are poorly deleterious (De Carufel et al. 2015). As described above, GAGs have a unique ability to modulate the amyloid assembly and/or to interact with pre-fibrillar species, the inferred toxic species of the amyloidogenic cascade. Accordingly, GAGs most likely play important roles in the etiology of many amyloidrelated diseases, an avenue of active research.

Immunohistochemical analysis revealed that heparan sulfate co-localizes with IAPP amyloids in pancreatic islets of patients afflicted with type II diabetes (Young et al. 1992). Additionally, NMR studies showed that heparin interacts with the positively charged N-terminal domain of IAPP (Jha et al. 2011) whereas isothermal titration calorimetry indicated a moderate affinity between IAPP and heparin (De Carufel et al. 2013). Considering that sulfated GAGs interact avidly with IAPP and modulate its fibrillization, the influence of GAGs on IAPP cytotoxicity has been addressed. When applied to isolated pancreatic $\beta$-cells, IAPP induces cell death by mecha- 
nisms that are still not clearly understood (Cao et al. 2013). Strikingly, soluble heparin and its synthetic fragments reduced the cytotoxicity induced by IAPP (De Carufel et al. 2013; Jha et al. 2011). The role of cell surface GAGs in IAPP toxicity was investigated using CHO pgs-A-745 cells, which lack GAGs on the outer leaflet of their plasma membrane due to a deficiency in xylosyltransferase, a key enzyme in PG biosynthesis. The absence of cell surface GAGs did not reduce the vulnerability of CHO cells towards IAPP (De Carufel et al. 2013). In contrast, isolated islets of double-transgenic mice overexpressing both heparinase and hIAPP had less amyloid deposition than the islets isolated from hIAPP transgenic mice (Oskarsson et al. 2015). The relation between sulfated GAGs and amyloid-related cytotoxicity was also investigated with A $\beta$. By means of HEK293 cells overexpressing heparinase, it was reported that cell surface GAGs mediate internalization and cytotoxicity of $A \beta$ (Sandwall et al. 2010). These studies indicate that sulfated GAGs are key components for amyloid deposition although their roles in cytotoxicity remain somewhat contradictory.

Tauopathies are neurodegenerative diseases associated with the deposition of tau protein into filamentous aggregates (Holmes et al. 2013). It is known that cytosolic tau assemblies are released in the extracellular space and propagate to other neuronal cells by macropinocytosis, where they induce fibrillization of native tau proteins in a prion-like mechanism (Kfoury et al. 2012). In addition, tau displays a heparin binding motif, suggestive of a possible interaction with cell surface GAGs (Goedert et al. 1996). Strikingly, extracellular tau proteins co-localize with PGs and the removal of GAG chains with heparinase treatment reduces cellular uptake of tau aggregates in murine neural cells (Holmes et al. 2013). To further evaluate the contributions of GAGs in tau propagation, the authors used a co-culture assay where donor and acceptor cells expressed tau proteins with different fluorophores. By FRET, it was observed that when cells are 
treated with heparinase, a significant decrease of propagation occurs. A similar effect of GAGmediated aggregates propagation was reported for the prion protein (Wolf et al. 2015). Furthermore, in transmissible spongiform encephalopathies the presence of an abnormally folded conformer of the prion protein induces the conversion of the normal prion protein cellular $\operatorname{PrP}^{\mathrm{C}}$ into the pathogenic form $\mathrm{PrP}^{\mathrm{Sc}}$. Although the mechanism underlying this conversion remains elusive, it is known that polyanions are able to enhance the conversion of $\operatorname{PrP}^{\mathrm{C}}$ into $\operatorname{PrP}^{\mathrm{Sc}}(\mathrm{Ma}$ 2012). Specifically, it has been observed in vitro that heparan sulfate stimulates the formation of $\mathrm{PrP}^{\mathrm{Sc}}$ in absence of amyloidogenic seeds (Wong et al. 2001).

Although amyloids have been historically associated with degenerative diseases, recent studies have shown the existence of functional amyloid assemblies (Fowler et al. 2007). Peptide hormones are known to be stored under a very high concentration in secretory granules in an aggregated state. Interestingly, it was reported that this aggregated state is closely related to an amyloid conformation, rich in cross- $\beta$-sheets (Maji et al. 2009). Immunohistochemical studies with mouse pituitary tissues revealed a positive binding of the amyloid-sensitive dye thioflavin $\mathrm{S}$ in the anterior and posterior lobes that co-localizes with hormone-specific antibodies. Moreover, by combining biophysical approaches the authors showed that among the 42 peptides studied, 31 formed amyloid fibrils in vitro in presence of heparin, employed as a model of the sulfated GAGs found in the secretory granules (Maji et al. 2009). It was recently shown in rat hypothalamus that somatostatin (SST) is stored within the secretory granules as amyloid fibrils (Anoop et al. 2014). Particularly, the authors revealed that these SST fibrils assembled in presence of heparin are able to release biologically active monomers. In sharp contrast, under in vitro conditions that recapitulate the conditions of secretory granules, no evidence of an amyloid-like structure was observed for the peptide hormone prolactin in presence of GAGs (Christensen et al. 2016). 
The observed aggregates did not bind the amyloid sensitive dye ThT and no amyloidcharacteristic was observed by infrared spectroscopy and TEM. Thus, the physiological significance of GAG-mediated amyloid assembly in the context of peptide hormone storage is still the subject of active debate and further studies are required.

\section{Conclusion}

In this review, we presented in detail the contributions of sulfated GAGs in amyloid assembly and we discussed the potential pathophysiological and functional roles of GAG-mediated amyloidogenesis. These polyanionic polysaccharides have been shown to enhance and/or to prompt the assembly of a wide diversity of proteins, from small intrinsically disordered peptides to large globular proteins and from aggregation-prone polypeptides to highly soluble peptidic chains. Although the number of studies that have reported a positive effect of GAGs on amyloid fibril formation is important and impressive, clear mechanistic details remain elusive. Taking into account the available data, we suggested that GAGs accelerate amyloid assembly by one or a combination of models, including GAG-directed monomer conversion and GAG-mediated quaternary structural conversion. These above-proposed models constitute a starting point to mechanistically define the role of GAGs in amyloid assembly, a highly relevant and unsolved biomedical issue. Above all, it will be important to pursue the (patho)physiological significance of GAG-mediated amyloid formation in relevant cellular and animal models. 


\section{Acknowledgments}

The authors apologize to all research groups whose contributions could not be cited due to space limitations. This work was supported by grants from the Natural Sciences and Engineering Research Council of Canada (NSERC) and the Fonds de Recherche du Québec-Nature et technologies (FRQNT). 


\section{Figure Legends}

Fig 1. (A) Representative transmission electron microscopy (TEM) image of amyloid fibrils obtained from the self-assembly of IAPP. (B) Schematic representation of the hierarchical organization of amyloid fibrils and of the general cross- $\beta$-sheet quaternary structure.

Fig 2. Schematic representation of amyloid assembly. The nucleation dependent polymerization mechanism is characterized by three distinct phases: $(i)$ the lag phase, (ii) the elongation phase and (iii) the saturation phase. Presence of GAGs in the assembly reaction shortens the lag phase and/or increases the rate of amyloid elongation (red dashed line).

Fig 3. Representative chemical structure of (A) heparin/heparan sulfate and (B) chondroitin sulfate. $(\mathrm{A}, \mathrm{B}) \mathrm{R}_{1}:-\mathrm{H}$ or $-\mathrm{SO}_{3}{ }^{-}$and $\mathrm{R}_{2}:-\mathrm{SO}_{3}{ }^{-}$or $-\mathrm{COCH}_{3}$. (A) The distinction between heparin and heparin sulfate is the number of SO3- groups per disaccharide unit, with heparin having an average of 2.7 sulfate groups per disaccharide and heparan sulfate around 1 sulfate per disaccharide. 
Table 1 Polypeptides whose amyloid assembly is accelerated and/or promoted by the presence of sulfated glycosaminoglycans.

\begin{tabular}{|c|c|c|c|}
\hline Polypeptide & *Amyloidogenecity & Associated pathology & Reference \\
\hline hIAPP & + & Type II diabetes mellitus & (De Carufel et al. 2013) \\
\hline Amyloid- $\beta$ & + & Alzheimer’s disease & (Brunden et al. 1993) \\
\hline$\alpha$-synuclein & + & Parkinson's disease & (Holmes et al. 2013) \\
\hline ANF & + & Isolated atrial amyloidosis & (Millucci et al. 2011) \\
\hline Medin & + & Aortic medial amyloidosis & (Madine and Middleton 2010) \\
\hline $\mathrm{sCT}$ & $+/-$ & Therapeutic & (Malmos et al. 2016) \\
\hline $\mathrm{hCT}$ & + & Thyroid medullary carcinoma & (Itoh-Watanabe et al. 2013) \\
\hline VIP & - & None & (Maji et al. 2009) \\
\hline rIAPP & $+/-$ & None & (Wang and Raleigh 2014) \\
\hline $\operatorname{PLB}(1-23)$ & - & None & (Madine et al. 2013) \\
\hline$\beta$-endorphin & - & None & (Nespovitaya et al. 2016) \\
\hline Somatostatin & $+/-$ & None & (Anoop et al. 2014) \\
\hline $\operatorname{PrP}(106-126)$ & + & Fatal familial insomnia & (Bazar and Jelinek 2010) \\
\hline Gelsolin & + & Finnish-type familial amyloidosis & (Solomon et al. 2011) \\
\hline Transthyretin & $+/-$ & Familial amyloidosis & (Bourgault et al. 2011b) \\
\hline$\beta$-2-microglobulin & + & Dialysis-related amyloidosis & (Corlin et al. 2010) \\
\hline Serum amyloid A & $+/-$ & Rheumatoid arthritis & (Egashira et al. 2011) \\
\hline Apomyoglobin & $+/-$ & None & (Vilasi et al. 2011) \\
\hline Tau protein & + & Alzheimer's disease & (Luo et al. 2013) \\
\hline Acylphosphatase & - & None & (Motamedi-Shad et al. 2009) \\
\hline
\end{tabular}




\section{References}

Abedini, A., and Raleigh, D.P. 2006. Destabilization of human IAPP amyloid fibrils by proline mutations outside of the putative amyloidogenic domain: is there a critical amyloidogenic domain in human IAPP? Journal of molecular biology 355(2): 274-281. doi: 10.1016/j.jmb.2005.10.052.

Abedini, A., and Raleigh, D.P. 2009. A critical assessment of the role of helical intermediates in amyloid formation by natively unfolded proteins and polypeptides. Protein engineering, design \& selection : PEDS 22(8): 453-459. doi: 10.1093/protein/gzp036.

Abedini, A., Tracz, S.M., Cho, J.H., and Raleigh, D.P. 2006. Characterization of the heparin binding site in the $\mathrm{N}$-terminus of human pro-islet amyloid polypeptide: Implications for amyloid formation. Biochemistry 45: 9228-9237. doi: 10.1021/bi0510936.

Alexandrescu, A.T. 2005. Amyloid accomplices and enforcers. Protein science : a publication of the Protein Society 14(1): 1-12. doi: 10.1110/ps.04887005.

Ancsin, J.B. 2003. Amyloidogenesis: historical and modern observations point to heparan sulfate proteoglycans as a major culprit. Amyloid : the international journal of experimental and clinical investigation : the official journal of the International Society of Amyloidosis 10(2): 67-79.

Anoop, A., Ranganathan, S., Dhaked, B.D., Jha, N.N., Pratihar, S., Ghosh, S., Sahay, S., Kumar, S., Das, S., Kombrabail, M., Agarwal, K., Jacob, R.S., Singru, P., Bhaumik, P., Padinhateeri, R., Kumar, A., and Maji, S.K. 2014. Elucidating the Role of Disulfide Bond on Amyloid Formation and Fibril Reversibility of Somatostatin-14: RELEVANCE TO ITS STORAGE AND SECRETION. Journal of Biological Chemistry 289: 16884-16903. doi: 10.1074/jbc.M114.548354.

Bazar, E., and Jelinek, R. 2010. Divergent heparin-induced fibrillation pathways of a prion amyloidogenic determinant. ChemBioChem 11: 1997-2002. doi: 10.1002/cbic.201000207.

Bemporad, F., and Chiti, F. 2012. Protein misfolded oligomers: experimental approaches, mechanism of formation, and structure-toxicity relationships. Chem Biol 19(3): 315-327. doi: 10.1016/j.chembiol.2012.02.003.

Bhak, G., Lee, S., Park, J.W., Cho, S., and Paik, S.R. 2010. Amyloid hydrogel derived from curly protein fibrils of alpha-synuclein. Biomaterials 31(23): 5986-5995. doi: 10.1016/j.biomaterials.2010.03.080.

Bishop, J.R., Schuksz, M., and Esko, J.D. 2007. Heparan sulphate proteoglycans fine-tune mammalian physiology. Nature 446(7139): 1030-1037. doi: 10.1038/nature05817.

Blanco, L.P., Evans, M.L., Smith, D.R., Badtke, M.P., and Chapman, M.R. 2012. Diversity, biogenesis and function of microbial amyloids. Trends in microbiology 20(2): 66-73. doi: 10.1016/j.tim.2011.11.005.

Bourgault, S., Choi, S., Buxbaum, J.N., Kelly, J.W., Price, J.L., and Reixach, N. 2011a. Mechanisms of transthyretin cardiomyocyte toxicity inhibition by resveratrol analogs. Biochemical and biophysical research communications 410(4): 707-713. doi: 10.1016/j.bbrc.2011.04.133.

Bourgault, S., Solomon, J.P., Reixach, N., and Kelly, J.W. 2011b. Sulfated glycosaminoglycans accelerate transthyretin amyloidogenesis by quaternary structural conversion. Biochemistry 50(6): 1001-1015. doi: 10.1021/bi101822y.

Branco, M.C., Sigano, D.M., and Schneider, J.P. 2011. Materials from peptide assembly: towards the treatment of cancer and transmittable disease. Current opinion in chemical biology 15(3): 427-434. doi: 10.1016/j.cbpa.2011.03.021.

Brunden, K.R., Richter-Cook, N.J., Chaturvedi, N., and Frederickson, R.C.A. 1993. pH-dependent binding of synthetic beta-amyloid peptides to glycosaminoglycans. Journal of Neurochemistry 61: 2147-2154. doi: 10.1111/j.1471-4159.1993.tb07453.x.

Bulawa, C.E., Connelly, S., Devit, M., Wang, L., Weigel, C., Fleming, J.A., Packman, J., Powers, E.T., Wiseman, R.L., Foss, T.R., Wilson, I.A., Kelly, J.W., and Labaudiniere, R. 2012. Tafamidis, a potent and selective transthyretin kinetic stabilizer that inhibits the amyloid cascade. Proceedings of the National 
Academy of Sciences of the United States of America 109(24): 9629-9634. doi: 10.1073/pnas.1121005109.

Cao, P., Marek, P., Noor, H., Patsalo, V., Tu, L.-H., Wang, H., Abedini, A., and Raleigh, D.P. 2013. Islet amyloid: From fundamental biophysics to mechanisms of cytotoxicity. FEBS letters 587(8): 1106-1118. doi: 10.1016/j.febslet.2013.01.046.

Cardin, A.D., and Weintraub, H.J. 1989. Molecular modeling of protein-glycosaminoglycan interactions. Arteriosclerosis (Dallas, Tex.) 9(1): 21-32.

Castillo, G.M., Cummings, J.A., Yang, W., Judge, M.E., Sheardown, M.J., Rimvall, K., Hansen, J.B., and Snow, A.D. 1998. Sulfate content and specific glycosaminoglycan backbone of perlecan are critical for perlecan's enhancement of islet amyloid polypeptide (amylin) fibril formation. Diabetes 47(4): 612-620.

Chiti, F., and Dobson, C.M. 2006. Protein misfolding, functional amyloid, and human disease. Annual review of biochemistry 75: 333-366. doi: 10.1146/annurev.biochem.75.101304.123901.

Christensen, L.F., Malmos, K.G., Christiansen, G., and Otzen, D.E. 2016. A Complex Dance: The Importance of Glycosaminoglycans and Zinc in the Aggregation of Human Prolactin. Biochemistry 55(26): 3674-3684. doi: 10.1021/acs.biochem.6b00153.

Cohen, F.E., and Kelly, J.W. 2003. Therapeutic approaches to protein-misfolding diseases. Nature 426(6968): 905-909. doi: 10.1038/nature02265.

Cohlberg, J.A., Li, J., Uversky, V.N., and Fink, A.L. 2002. Heparin and other glycosaminoglycans stimulate the formation of amyloid fibrils from alpha-synuclein in vitro. Biochemistry 41(5): 1502-1511.

Colvin, M.T., Silvers, R., Ni, Q.Z., Can, T.V., Sergeyev, I., Rosay, M., Donovan, K.J., Michael, B., Wall, J., Linse, S., and Griffin, R.G. 2016. Atomic Resolution Structure of Monomorphic Abeta42 Amyloid Fibrils. J Am Chem Soc 138(30): 9663-9674. doi: 10.1021/jacs.6b05129.

Connelly, S., Choi, S., Johnson, S.M., Kelly, J.W., and Wilson, I.A. 2010. Structure-based design of kinetic stabilizers that ameliorate the transthyretin amyloidoses. Current opinion in structural biology 20(1): 5462. doi: 10.1016/j.sbi.2009.12.009.

Corlin, D.B., Johnsen, C.K., Nissen, M.H., and Heegaard, N.H.H. 2010. Glycosaminoglycans enhance the fibrillation propensity of the $\beta$-2-microglobulin cleavage variant - deltaK58-beta2m. Biochemical and Biophysical Research Communications 402: 247-251. doi: 10.1016/j.bbrc.2010.10.008.

De Carufel, C.A., Nguyen, P.T., Sahnouni, S., and Bourgault, S. 2013. New insights into the roles of sulfated glycosaminoglycans in islet amyloid polypeptide amyloidogenesis and cytotoxicity. Biopolymers 100(6): 645-655. doi: 10.1002/bip.22243.

De Carufel, C.A., Quittot, N., Nguyen, P.T., and Bourgault, S. 2015. Delineating the Role of Helical Intermediates in Natively Unfolded Polypeptide Amyloid Assembly and Cytotoxicity. Angew Chem Int Ed Engl. doi: 10.1002/anie.201507092.

DeWitt, D.A., Silver, J., Canning, D.R., and Perry, G. 1993. Chondroitin sulfate proteoglycans are associated with the lesions of Alzheimer's disease. Experimental neurology 121(2): 149-152. doi: 10.1006/exnr.1993.1081.

Egashira, M., Takase, H., Yamamoto, I., Tanaka, M., and Saito, H. 2011. Identification of regions responsible for heparin-induced amyloidogenesis of human serum amyloid $A$ using its fragment peptides. Archives of Biochemistry and Biophysics 511: 101-106. doi: 10.1016/j.abb.2011.04.019.

Fowler, D.M., Koulov, A.V., Alory-Jost, C., Marks, M.S., Balch, W.E., and Kelly, J.W. 2006. Functional amyloid formation within mammalian tissue. PLoS biology 4(1): e6. doi: 10.1371/journal.pbio.0040006.

Fowler, D.M., Koulov, A.V., Balch, W.E., and Kelly, J.W. 2007. Functional amyloid--from bacteria to humans. Trends in biochemical sciences 32(5): 217-224. doi: 10.1016/j.tibs.2007.03.003.

Fraser, P.E., Darabie, A.A., and McLaurin, J.A. 2001. Amyloid-beta interactions with chondroitin sulfatederived monosaccharides and disaccharides. implications for drug development. The Journal of biological chemistry 276(9): 6412-6419. doi: 10.1074/jbc.M008128200. 
Gellermann, G.P., Appel, T.R., Tannert, A., Radestock, A., Hortschansky, P., Schroeckh, V., Leisner, C., Lutkepohl, T., Shtrasburg, S., Rocken, C., Pras, M., Linke, R.P., Diekmann, S., and Fandrich, M. 2005. Raft lipids as common components of human extracellular amyloid fibrils. Proceedings of the National Academy of Sciences of the United States of America 102(18): 6297-6302. doi: 10.1073/pnas.0407035102.

Goedert, M., Jakes, R., Spillantini, M.G., Hasegawa, M., Smith, M.J., and Crowther, R.A. 1996. Assembly of microtubule-associated protein tau into Alzheimer-like filaments induced by sulphated glycosaminoglycans. Nature 383(6600): 550-553. doi: 10.1038/383550a0.

Handel, T.M., Johnson, Z., Crown, S.E., Lau, E.K., and Proudfoot, A.E. 2005. Regulation of protein function by glycosaminoglycans--as exemplified by chemokines. Annual review of biochemistry 74: 385410. doi: 10.1146/annurev.biochem.72.121801.161747.

Hileman, R.E., Fromm, J.R., Weiler, J.M., and Linhardt, R.J. 1998. Glycosaminoglycan-protein interactions: Definition of consensus sites in glycosaminoglycan binding proteins. BioEssays 20: 156-167. doi: 10.1002/(SICI)1521-1878(199802)20:2<156::AID-BIES8>3.0.CO;2-R.

Holmes, B.B., DeVos, S.L., Kfoury, N., Li, M., Jacks, R., Yanamandra, K., Ouidja, M.O., Brodsky, F.M., Marasa, J., Bagchi, D.P., Kotzbauer, P.T., Miller, T.M., Papy-Garcia, D., and Diamond, M.I. 2013. Heparan sulfate proteoglycans mediate internalization and propagation of specific proteopathic seeds. Proceedings of the National Academy of Sciences of the United States of America 110: E3138-3147. doi: 10.1073/pnas.1301440110.

Hurshman, A.R., White, J.T., Powers, E.T., and Kelly, J.W. 2004. Transthyretin aggregation under partially denaturing conditions is a downhill polymerization. Biochemistry 43(23): 7365-7381. doi: 10.1021/bi049621l.

lannuzzi, C., Irace, G., and Sirangelo, I. 2015. The effect of glycosaminoglycans (GAGs) on amyloid aggregation and toxicity. Molecules 20(2): 2510-2528. doi: 10.3390/molecules20022510.

Inoue, S., Kuroiwa, M., Saraiva, M.J., Guimaraes, A., and Kisilevsky, R. 1998. Ultrastructure of familial amyloid polyneuropathy amyloid fibrils: examination with high-resolution electron microscopy. Journal of structural biology 124(1): 1-12. doi: 10.1006/jsbi.1998.4052.

Itoh-Watanabe, H., Kamihira-Ishijima, M., Javkhlantugs, N., Inoue, R., Itoh, Y., Endo, H., Tuzi, S., Saitô, H., Ueda, K., and Naito, A. 2013. Role of aromatic residues in amyloid fibril formation of human calcitonin by solid-state 13C NMR and molecular dynamics simulation. Physical chemistry chemical physics : PCCP 15: 8890-8901. doi: 10.1039/c3cp44544e.

Jha, S., Patil, S.M., Gibson, J., Nelson, C.E., Alder, N.N., and Alexandrescu, A.T. 2011. Mechanism of amylin fibrillization enhancement by heparin. The Journal of biological chemistry 286(26): 22894-22904. doi: $10.1074 /$ jbc.M110.215814.

Kayed, R., Head, E., Thompson, J.L., McIntire, T.M., Milton, S.C., Cotman, C.W., and Glabe, C.G. 2003. Common structure of soluble amyloid oligomers implies common mechanism of pathogenesis. Science 300(5618): 486-489. doi: 10.1126/science.1079469.

Kfoury, N., Holmes, B.B., Jiang, H., Holtzman, D.M., and Diamond, M.I. 2012. Trans-cellular propagation of Tau aggregation by fibrillar species. J Biol Chem 287(23): 19440-19451. doi: 10.1074/jbc.M112.346072.

Kisilevsky, R. 2000. The relation of proteoglycans, serum amyloid $P$ and apo $E$ to amyloidosis current status, 2000. Amyloid : the international journal of experimental and clinical investigation : the official journal of the International Society of Amyloidosis 7(1): 23-25.

Lee, J., Culyba, E.K., Powers, E.T., and Kelly, J.W. 2011. Amyloid- $\beta$ Forms Fibrils by Nucleated Conformational Conversion of Oligomers. Nature chemical biology 7(9): 602-609. doi: 10.1038/nchembio.624. 
Lu, J.-X., Qiang, W., Yau, W.-M., Schwieters, C.D., Meredith, S.C., and Tycko, R. 2013. Molecular structure of $\beta$-amyloid fibrils in Alzheimer's disease brain tissue. Cell 154(6): 10.1016/j.cell.2013.1008.1035. doi: 10.1016/j.cell.2013.08.035.

Luo, Y., Dinkel, P., Yu, X., Margittai, M., Zheng, J., Nussinov, R., Wei, G., and Ma, B. 2013. Molecular insights into the reversible formation of tau protein fibrils. Chem Commun (Camb) 49(34): 3582-3584. doi: 10.1039/c3cc00241a.

Ma, J. 2012. The role of cofactors in prion propagation and infectivity. PLoS pathogens 8(4): e1002589. doi: 10.1371/journal.ppat.1002589.

Madine, J., Davies, H.A., Hughes, E., and Middleton, D.A. 2013. Heparin promotes the rapid fibrillization of a peptide with low intrinsic amyloidogenicity. Biochemistry 52(50): 8984-8992. doi: 10.1021/bi401231u.

Madine, J., and Middleton, D.A. 2010. Comparison of aggregation enhancement and inhibition as strategies for reducing the cytotoxicity of the aortic amyloid polypeptide medin. European Biophysics Journal 39: 1281-1288. doi: 10.1007/s00249-010-0581-3.

Maji, S.K., Perrin, M.H., Sawaya, M.R., Jessberger, S., Vadodaria, K., Rissman, R.A., Singru, P.S., Nilsson, K.P., Simon, R., Schubert, D., Eisenberg, D., Rivier, J., Sawchenko, P., Vale, W., and Riek, R. 2009. Functional amyloids as natural storage of peptide hormones in pituitary secretory granules. Science 325(5938): 328-332. doi: 10.1126/science.1173155.

Malmos, K.G., Bjerring, M., Jessen, C.M., Nielsen, E.H.T., Poulsen, E.T., Christiansen, G., Vosegaard, T., Skrydstrup, T., Enghild, J.J., Pedersen, J.S., and Otzen, D.E. 2016. How Glycosaminoglycans Promote Fibrillation of Salmon Calcitonin. Journal of Biological Chemistry: jbc.M116.715466. doi: 10.1074/jbc.M116.715466.

McLaughlin, R.W., De Stigter, J.K., Sikkink, L.A., Baden, E.M., and Ramirez-Alvarado, M. 2006. The effects of sodium sulfate, glycosaminoglycans, and Congo red on the structure, stability, and amyloid formation of an immunoglobulin light-chain protein. Protein science : a publication of the Protein Society 15(7): 1710-1722. doi: 10.1110/ps.051997606.

McLaurin, J., Franklin, T., Zhang, X., Deng, J., and Fraser, P.E. 1999. Interactions of Alzheimer amyloidbeta peptides with glycosaminoglycans effects on fibril nucleation and growth. European journal of biochemistry / FEBS 266(3): 1101-1110.

Millucci, L., Paccagnini, E., Ghezzi, L., Bernardini, G., Braconi, D., Laschi, M., Consumi, M., Spreafico, A., Tanganelli, P., Lupetti, P., Magnani, A., and Santucci, A. 2011. Different factors affecting human ANP amyloid aggregation and their implications in congestive heart failure. PLoS ONE 6: 1-12. doi: 10.1371/journal.pone.0021870.

Moremen, K.W., Tiemeyer, M., and Nairn, A.V. 2012. Vertebrate protein glycosylation: diversity, synthesis and function. Nature reviews. Molecular cell biology 13(7): 448-462. doi: 10.1038/nrm3383.

Motamedi-Shad, N., Monsellier, E., and Chiti, F. 2009. Amyloid formation by the model protein muscle acylphosphatase is accelerated by heparin and heparan sulphate through a scaffolding-based mechanism. Journal of biochemistry 146(6): 805-814. doi: 10.1093/jb/mvp128.

Muthukumar, M. 2004. Theory of counter-ion condensation on flexible polyelectrolytes: Adsorption mechanism. Journal of Chemical Physics 120: 9343-9350. doi: 10.1063/1.1701839.

Nelson, R., Sawaya, M.R., Balbirnie, M., Madsen, A.O., Riekel, C., Grothe, R., and Eisenberg, D. 2005. Structure of the cross-[beta] spine of amyloid-like fibrils. Nature 435(7043): 773-778. doi: http://www.nature.com/nature/journal/v435/n7043/suppinfo/nature03680 S1.html.

Nespovitaya, N., Gath, J., Barylyuk, K., Seuring, C., Meier, B.H., and Riek, R. 2016. Dynamic Assembly and Disassembly of Functional $\beta$-Endorphin Amyloid Fibrils. Journal of the American Chemical Society 138: 846-856. doi: 10.1021/jacs.5b08694. 
Nguyen, K., and Rabenstein, D.L. 2016. Interaction of the Heparin-Binding Consensus Sequence of $\beta$ Amyloid Peptides with Heparin and Heparin-Derived Oligosaccharides. The Journal of Physical Chemistry B: acs.jpcb.5b12235. doi: 10.1021/acs.jpcb.5b12235.

Nguyen, P.T., Andraka, N., De Carufel, C.A., and Bourgault, S. 2015. Mechanistic Contributions of Biological Cofactors in Islet Amyloid Polypeptide Amyloidogenesis. Journal of diabetes research 2015: 515307. doi: 10.1155/2015/515307.

Noborn, F., O'Callaghan, P., Hermansson, E., Zhang, X., Ancsin, J.B., Damas, A.M., Dacklin, I., Presto, J., Johansson, J., Saraiva, M.J., Lundgren, E., Kisilevsky, R., Westermark, P., and Li, J.-P. 2011. Heparan sulfate/heparin promotes transthyretin fibrillization through selective binding to a basic motif in the protein. Proceedings of the National Academy of Sciences of the United States of America 108: 55845589. doi: 10.1073/pnas.1101194108.

Ohishi, H., Skinner, M., Sato-Araki, N., Okuyama, T., Gejyo, F., Kimura, A., Cohen, A.S., and Schmid, K. 1990. Glycosaminoglycans of the hemodialysis-associated carpal synovial amyloid and of amyloid-rich tissues and fibrils of heart, liver, and spleen. Clinical chemistry 36(1): 88-91.

Oskarsson, M.E., Singh, K., Wang, J., Vlodavsky, I., Li, J.-p., and Westermark, G.T. 2015. Heparan Sulfate Proteoglycans Are Important for Islet Amyloid Formation and Islet Amyloid Polypeptide-induced Apoptosis. Journal of Biological Chemistry 290(24): 15121-15132. doi: 10.1074/jbc.M114.631697.

Paravastu, A.K., Leapman, R.D., Yau, W.M., and Tycko, R. 2008. Molecular structural basis for polymorphism in Alzheimer's beta-amyloid fibrils. Proc Natl Acad Sci U S A 105(47): 18349-18354. doi: 10.1073/pnas.0806270105.

Perez, M., Wandosell, F., Colaco, C., and Avila, J. 1998. Sulphated glycosaminoglycans prevent the neurotoxicity of a human prion protein fragment. The Biochemical journal 335 ( Pt 2): 369-374.

Petkova, A.T., Yau, W.-M., and Tycko, R. 2006. Experimental constraints on quaternary structure in Alzheimer's $\beta$-amyloid fibrils. Biochemistry 45(2): 498-512. doi: 10.1021/bi051952q.

Proudfoot, A.E.I., Fritchley, S., Borlat, F., Shaw, J.P., Vilbois, F., Zwahlen, C., Trkola, A., Marchant, D., Clapham, P.R., and Wells, T.N.C. 2001. The BBXB Motif of RANTES Is the Principal Site for Heparin Binding and Controls Receptor Selectivity. Journal of Biological Chemistry 276: 10620-10626. doi: 10.1074/jbc.M010867200.

Prusiner, S.B. 1982. Novel proteinaceous infectious particles cause scrapie. Science 216(4542): 136-144. Relini, A., De Stefano, S., Torrassa, S., Cavalleri, O., Rolandi, R., Gliozzi, A., Giorgetti, S., Raimondi, S., Marchese, L., Verga, L., Rossi, A., Stoppini, M., and Bellotti, V. 2008. Heparin strongly enhances the formation of beta2-microglobulin amyloid fibrils in the presence of type I collagen. The Journal of biological chemistry 283(8): 4912-4920. doi: 10.1074/jbc.M702712200.

Rudra, J.S., Tian, Y.F., Jung, J.P., and Collier, J.H. 2010. A self-assembling peptide acting as an immune adjuvant. Proceedings of the National Academy of Sciences of the United States of America 107(2): 622627. doi: 10.1073/pnas.0912124107.

Sandwall, E., O'Callaghan, P., Zhang, X., Lindahl, U., Lannfelt, L., and Li, J.-P. 2010. Heparan sulfate mediates amyloid-beta internalization and cytotoxicity. Glycobiology 20(5): 533-541. doi: 10.1093/glycob/cwp205.

Sawaya, M.R., Sambashivan, S., Nelson, R., Ivanova, M.I., Sievers, S.A., Apostol, M.I., Thompson, M.J., Balbirnie, M., Wiltzius, J.J., McFarlane, H.T., Madsen, A.O., Riekel, C., and Eisenberg, D. 2007. Atomic structures of amyloid cross-beta spines reveal varied steric zippers. Nature 447(7143): 453-457. doi: 10.1038/nature05695.

Solomon, J.P., Bourgault, S., Powers, E.T., and Kelly, J.W. 2011. Heparin binds 8 kDa gelsolin cross-betasheet oligomers and accelerates amyloidogenesis by hastening fibril extension. Biochemistry 50(13): 2486-2498. doi: 10.1021/bi101905n. 
Solomon, J.P., Page, L.J., Balch, W.E., and Kelly, J.W. 2012. Gelsolin amyloidosis: genetics, biochemistry, pathology and possible strategies for therapeutic intervention. Critical reviews in biochemistry and molecular biology 47(3): 282-296. doi: 10.3109/10409238.2012.661401.

Stenstad, T., Magnus, J.H., Kolset, S.O., Cornwell, G.G., 3rd, and Husby, G. 1991. Macromolecular properties of glycosaminoglycans in primary AL amyloid fibril extracts of lymphoid tissue origin. Scandinavian journal of immunology 34(5): 611-617.

Stewart, K.L., Hughes, E., Yates, E.A., Huang, T.-y., Lima, M.A., Rudd, R., Guerrini, M., Hung, S.-C., Radford, S.E., Middleton, D.A., Stewart, K.L., Hughes, E., Yates, E.A., Huang, T.-y., Lima, M.A., and Timothy, F.R. 2016. Atomic Details of the Interactions of Atomic Details of the Interactions of Glycosaminoglycans with Amyloid- $\beta$ Fibrils. Journal of the American Chemical Society 138: 8228-8331. doi: 10.1021/jacs.6b02816.

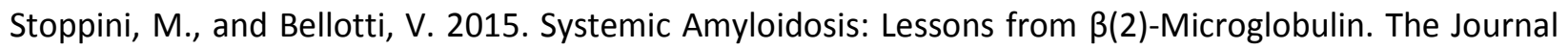
of Biological Chemistry 290(16): 9951-9958. doi: 10.1074/jbc.R115.639799.

Suk, J.Y., Zhang, F., Balch, W.E., Linhardt, R.J., and Kelly, J.W. 2006. Heparin accelerates gelsolin amyloidogenesis. Biochemistry 45(7): 2234-2242. doi: 10.1021/bi0519295.

Sunde, M., Serpell, L.C., Bartlam, M., Fraser, P.E., Pepys, M.B., and Blake, C.C. 1997. Common core structure of amyloid fibrils by synchrotron X-ray diffraction. J Mol Biol 273(3): 729-739. doi: 10.1006/jmbi.1997.1348.

Takase, H., Tanaka, M., Yamamoto, A., Watanabe, S., Takahashi, S., Nadanaka, S., Kitagawa, H., Yamada, T., and Mukai, T. 2016. Structural requirements of glycosaminoglycans for facilitating amyloid fibril formation of human serum amyloid A. Amyloid 6129: 1-9. doi: 10.3109/13506129.2016.1168292.

Tchoumi Neree, A., Nguyen, P.T., Chatenet, D., Fournier, A., and Bourgault, S. 2014. Secondary conformational conversion is involved in glycosaminoglycans-mediated cellular uptake of the cationic cell-penetrating peptide PACAP. FEBS letters 588(24): 4590-4596. doi: 10.1016/j.febslet.2014.10.029.

Theocharis, A.D., Skandalis, S.S., Gialeli, C., and Karamanos, N.K. 2016. Extracellular matrix structure. Advanced Drug Delivery Reviews 97: 4-27. doi: http://dx.doi.org/10.1016/i.addr.2015.11.001.

Tycko, R. 2014. Physical and structural basis for polymorphism in amyloid fibrils. Protein Science : A Publication of the Protein Society 23(11): 1528-1539. doi: 10.1002/pro.2544.

Tycko, R. 2015. Amyloid Polymorphism: Structural Basis and Neurobiological Relevance. Neuron 86(3): 632-645. doi: 10.1016/j.neuron.2015.03.017.

Vilasi, S., Sarcina, R., Maritato, R., de Simone, A., Irace, G., and Sirangelo, I. 2011. Heparin induces harmless fibril formation in amyloidogenic W7FW14F apomyoglobin and amyloid aggregation in wildtype protein In Vitro. PLoS ONE 6: e22076. doi: 10.1371/journal.pone.0022076.

Wälti, M.A., Ravotti, F., Arai, H., Glabe, C.G., Wall, J.S., Böckmann, A., Güntert, P., Meier, B.H., and Riek, R. 2016. Atomic-resolution structure of a disease-relevant $A \beta(1-42)$ amyloid fibril. Proceedings of the National Academy of Sciences of the United States of America 113(34): E4976-E4984. doi: 10.1073/pnas.1600749113.

Wang, H., Cao, P., and Raleigh, D.P. 2013. Amyloid formation in heterogeneous environments: Islet amyloid polypeptide glycosaminoglycan interactions. Journal of Molecular Biology 425: 492-505. doi: 10.1016/j.jmb.2012.11.003.

Wang, H., and Raleigh, D.P. 2014. The ability of insulin to inhibit the formation of amyloid by pro-islet amyloid polypeptide processing intermediates is significantly reduced in the presence of sulfated glycosaminoglycans. Biochemistry 53: 2605-2614. doi: 10.1021/bi4015488.

Wolf, H., Graßmann, A., Bester, R., Hossinger, A., Möhl, C., Paulsen, L., Groschup, M.H., Schätzl, H., and Vorberg, I. 2015. Modulation of Glycosaminoglycans Affects PrP(Sc) Metabolism but Does Not Block PrP(Sc) Uptake. Journal of Virology 89(19): 9853-9864. doi: 10.1128/JVI.01276-15. 
Wolwertz, M.L., Nguyen, P.T., Quittot, N., and Bourgault, S. 2016. Probing the role of lambda6 immunoglobulin light chain dimerization in amyloid formation. Biochimica et biophysica acta 1864(4): 409-418. doi: 10.1016/j.bbapap.2016.01.009.

Wong, C., Xiong, L.W., Horiuchi, M., Raymond, L., Wehrly, K., Chesebro, B., and Caughey, B. 2001. Sulfated glycans and elevated temperature stimulate $\operatorname{PrP}(\mathrm{Sc})$-dependent cell-free formation of proteaseresistant prion protein. The EMBO journal 20(3): 377-386. doi: 10.1093/emboj/20.3.377.

Yan, L.M., Tatarek-Nossol, M., Velkova, A., Kazantzis, A., and Kapurniotu, A. 2006. Design of a mimic of nonamyloidogenic and bioactive human islet amyloid polypeptide (IAPP) as nanomolar affinity inhibitor of IAPP cytotoxic fibrillogenesis. Proceedings of the National Academy of Sciences of the United States of America 103(7): 2046-2051. doi: 10.1073/pnas.0507471103.

Young, I.D., Ailles, L., Narindrasorasak, S., Tan, R., and Kisilevsky, R. 1992. Localization of the basement membrane heparan sulfate proteoglycan in islet amyloid deposits in type II diabetes mellitus. Archives of pathology \& laboratory medicine 116(9): 951-954. 


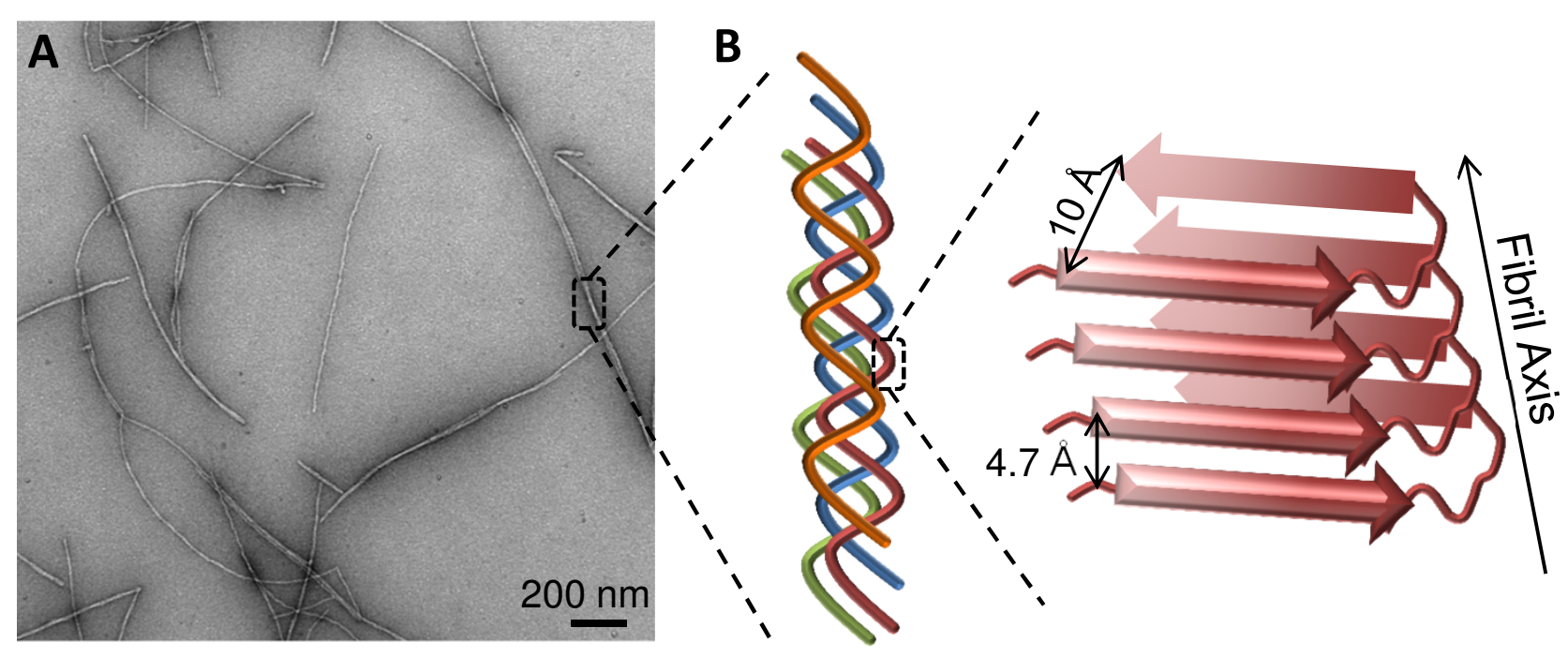




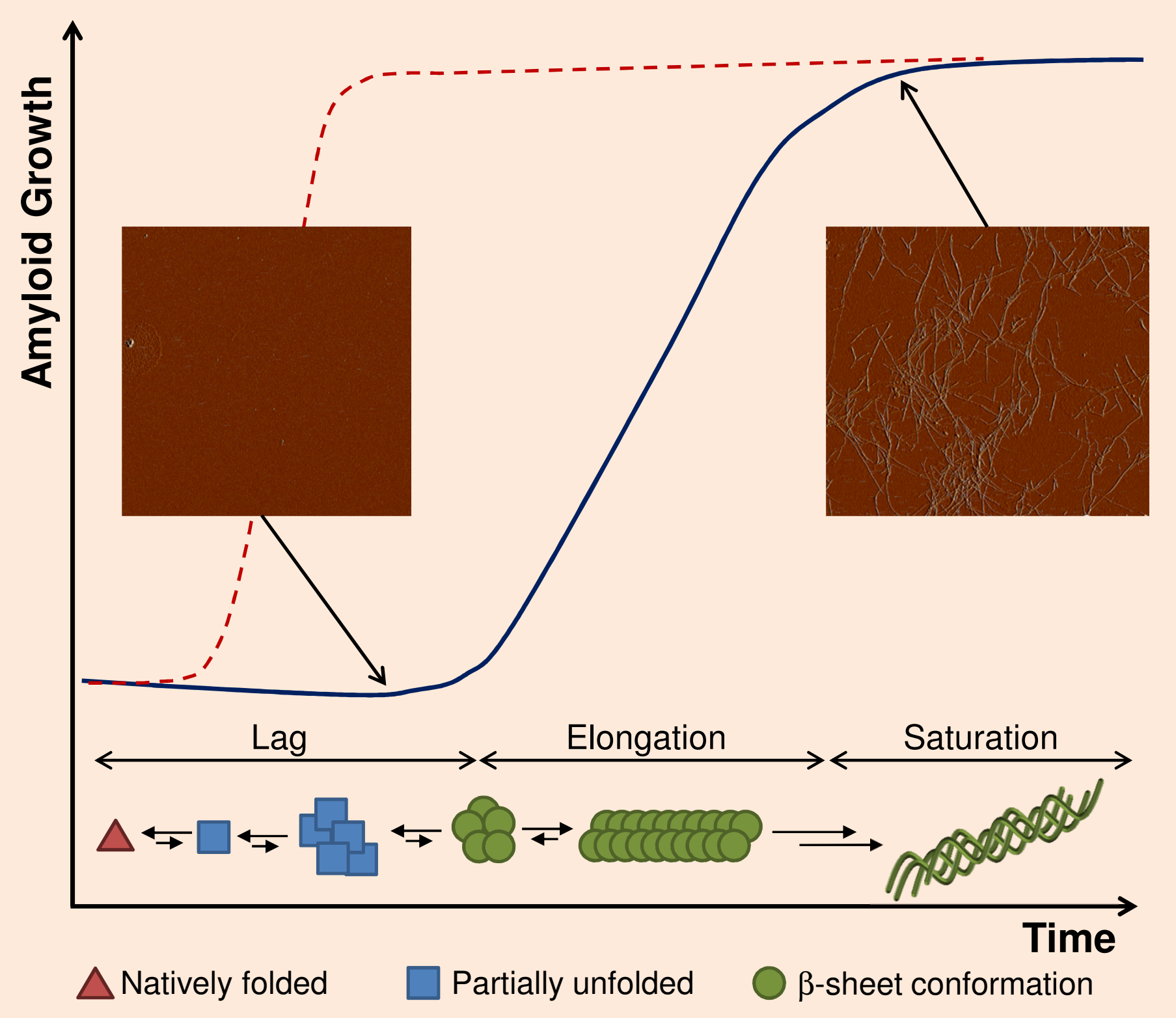



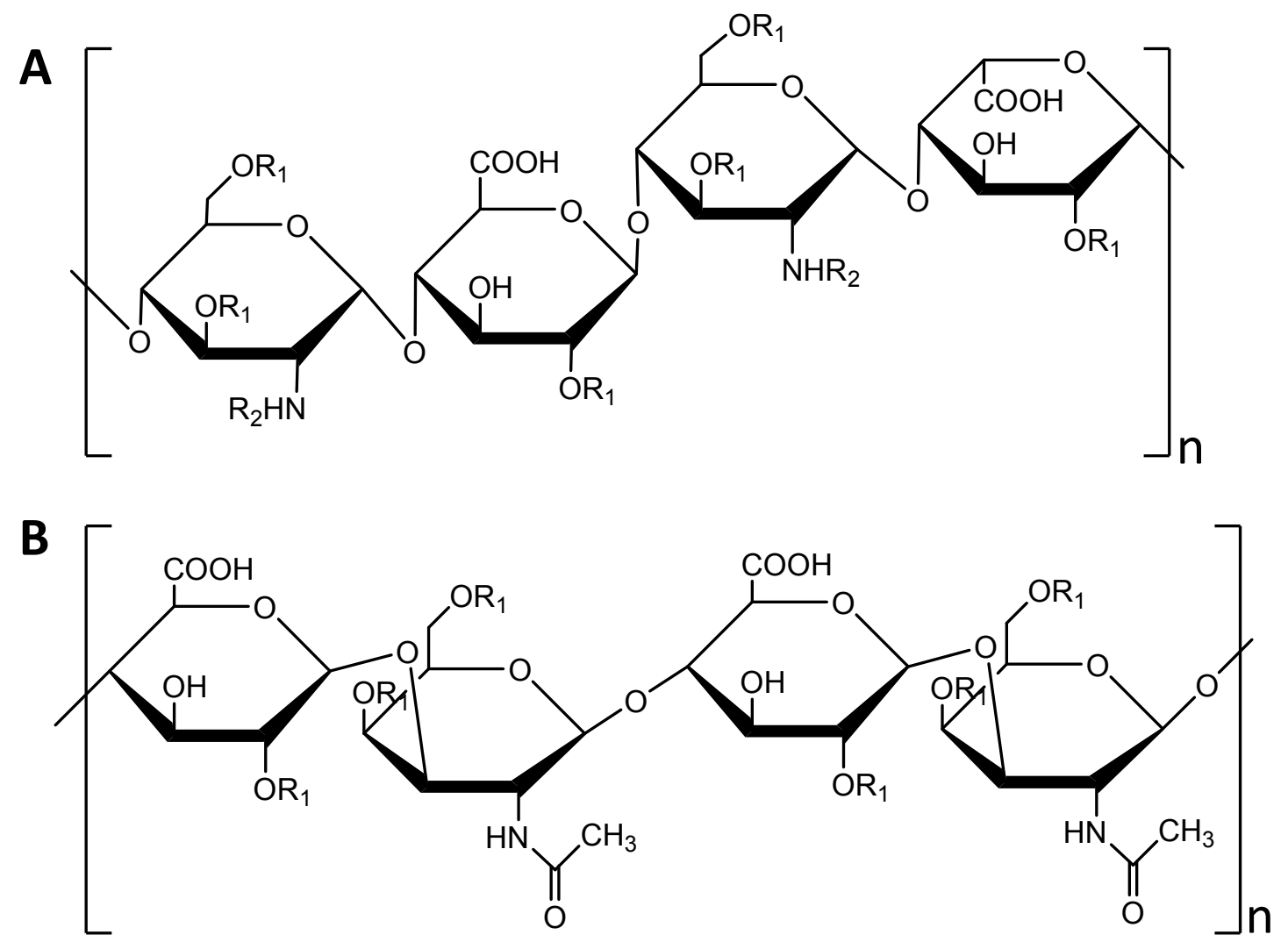